\section{A MICROSCOPE THAT LOOKS SIDEWAYS}

Stephen W. Carmichael, 1 Mayo Clinic

When most of us use a microscope, we are looking through a specimen, or more and more frequently, at the "top" surface. It usually doesn't occur to us to look sideways. But that is what was done recently in the laboratory of Charles Lieber at Harvard University. As reported by Daniel Frisbie, Lawrence Rozsnyai, Aleksandr Noy, Mark Wrighton, and Prof. Lieber, ${ }^{2}$ an atomic force microscope (AFM) was modified to perform as a "chemical force microscope" (CFM). With the CFM they were able to precisely measure adhesive and frictional forces. These forces can be thought of as acting parallel to the surface of the specimen, whereas most observations are made perpendicular to the surface.

They functionalized the tip of an AFM by covalently binding hydrophobic $\left(\mathrm{CH}_{3}\right)$ or hydrophilic $(\mathrm{COOH})$ molecules to the tip. It was reasoned that one 3 . should be able to predict the friction contrast in images of surfaces patterned with complimentary or noncomplimentary molecules. They constructed monolayers of molecules that terminated in two different functional groups using a lithographic technique. While hydrophobic or hydrophilic molecules were used in these experiments, it was pointed out that the approach can be generalized to other pairs of reactive molecules.

Using a Nanoscope III lateral force microscope, it was demonstrated that the force versus displacement curves were reproducibly larger when $\mathrm{COOH}$ was on both the tip and the specimen, smaller when $\mathrm{CH}_{3}$ was on both, and smallest when the interaction was between $\mathrm{CH}_{3}$ and $\mathrm{COOH}$. This was interpreted to represent the interaction between hydrophilic groups, which can form hydrogen bonds, is greater than between hydrophobic groups, and interactions between the two different functional groups is weakest. It was calculated that an individual measurement was over an area of about $10 \mathrm{~nm}^{2}$, representing about 50 functional groups on the sample and tip. Spatial resolution of under $10 \mathrm{~nm}$ was predicted.

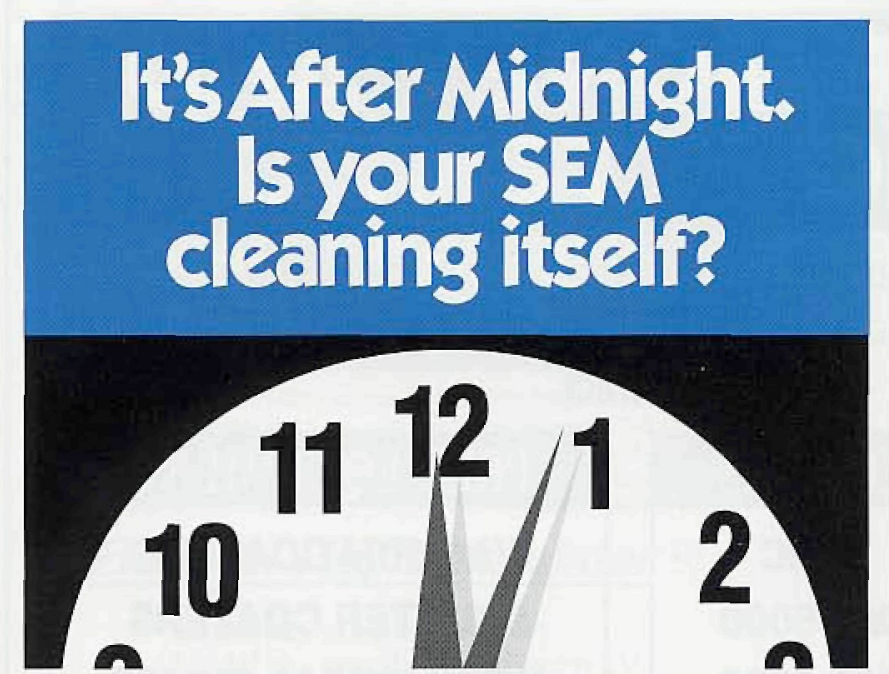

It would be if you had the SEM-CLEAN ${ }^{\top \mathrm{T}}$ anti-contamination system. Overnight, the inexpensive SEM-CLEAN system uses a Nitrogen purge to clean your electron microscope. Its active cleaning action removes oils and other adsorbed contaminants from the walls of the chamber and carries them to the roughing pump. Result? Significant reductions in, even elimination of, sample-contamination, raster burns and oil buildup on EDS windows. Over 50 satisfied SEM-CLEAN users are our best references. For a list and complete details, call or write today.

\section{SEM-CLEAN"' Stops the Oil}

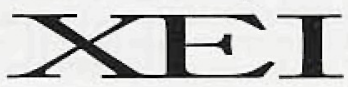

S C I E N T I F I C

3124 Wessex Way, Redwood City, CA, U.S.A 94061 415-369-0133 - Fax 415-363-1659
The potential applications of the CFM are legion. Molecular aspects of adhesion and lubrication, which are poorly understood, can now be examined more closely. In an accompanying article, ${ }^{3}$ it was suggested that an array of potential drug molecules could be spread on a surface, then scanned with a tip that had been functionalized with a receptor molecule of interest. The "drug" that had the strongest interaction with the receptor could be quickly revealed.

With the new CFM at our disposal, we will be taking a new look at problems now; a sideways look!

1. The author gratefully acknowledges Charles Lieber, Harvard University, for reviewing this article.

2. Frisbie, C.D., L.F. Rozsnyai, A. Noy, M.S. Wrighton, and C.M. Lieber, Functional group imaging by chemical force microscopy, Science 265:2071-2074, 1994.

Kaiser, J., A sideways look at chemical activity, Science 265:2010, 1994.

\section{"A LITTLE NONSENSE NOW AND THEN IS RELISHED BY THE WISEST MEN"} Sterling $P$. Newberry, Consultant

This familiar saying may be a little too risque for sober scientists but surely all of us can accept a substitution of the word humor for the word nonsense. For humor is based on a sense of proportion and fitness of relationships, which is the very essence of the scientific obligation to interpret what we observe. In fact, many of our colleagues insert humorous slides in their very serious talks to help wake up the audience and give them an association for remembering a key point. Do we also remember to use this power of humor when teaching, or otherwise communicating with, a lay audience?

Like it or not we are all required to be teachers to our own circle of support people and should furthermore take advantage of any opportunity to educate the world at large about our work. I should like to give a few examples from my own experience in teaching electron optical practice:

On cleanliness, "Little children who wash their hands on towels, grow up to put their bare hands on clean electron optical parts."

On the importance of vacuum, "Electron Optics and vacuum, one and inseparable, both now and forever."

To help remember the cross over angle of the single potential lens:
It's 54-40 if you are wanting to fight
But 54-44 if you would rather be right
About the field that's presented
To the electron in its flight
Through the Einzel Lens center
From left or from right."

I have observed that many other scientist employ humor to enrich their presentations. Among microscopists, Sara Miller, of Duke Medical center, employs humor brillianily. As an MSA speaker with the goal of presenting a through over view of the field of "Diagnostic Virology by Electron Microscopy", she has developed the following format. Sara employs two projectors on side by side screens. One carries the outline of her talk interspersed with her serious slides. The other is used to show the audience where the detailed discussion fits into the overall picture or to show a chart or table connected with the item under discussion. With superb timing the second screen suddenly displays a cartoon or photograph which is uproariously funny and is a take off on the technical term or procedure which the audience needs to concentrate upon. Should she lack an appropriate photograph or cartoon by some one like Gary Larson, she photographs a friend or even herself in a charade to form a pun on the word or concept. Before long the audience is sitting on the edge of their seats wondering what is coming next. Sara has taken what could be a very intricate and dull lecture and turned it into a memorable learning experience using materials which any one can readily acquire.

A somber note: I was disappointed to learn that Gary Larson will soon retire from cartooning. Perhaps some of our readers would like to ty their hand at scientific cartooning. 


\section{The smaller your problem, the better we look}
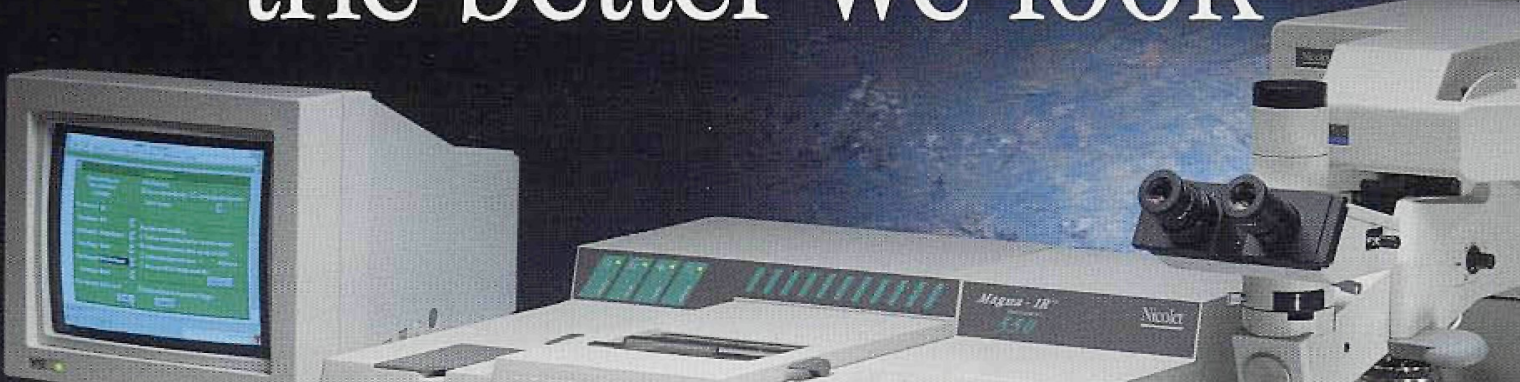

通

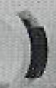

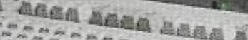

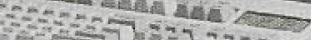

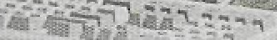

As the inventors and innovators of IR microspectroscopy,

Nicolet and Spectra-Tech have more systems helping more people solve their analytical problems than all other vendors combined!

Whether you are analyzing the layers in a multi-layer film, searching for the contaminant that made your part fail, identifying the origin of trace evidence or researching new adhesive bonds, Nicolet and Spectra-Tech have an infrared microscope to fit your needs and your budget - from the basic Laboratory IR-Plan ${ }^{\circledast}$ microscope to the high performance Nic-Plan ${ }^{\text {TM }}$ research microscope.

We add dimension to the information you collect with advanced capabilities like ATR and grazing angle microscopy, microscope mapping and video capture. Proprietary technology that allows you to analyze virtually any sample in reflectance as well as transmittance.

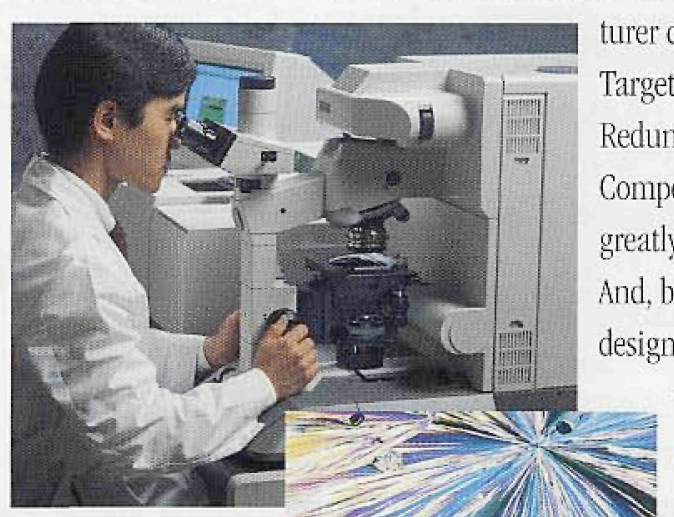
urer can provide you with patented argeting '", On-Axis Design, Redundant Aperturing ${ }^{\infty}$ and Sample Compensation " technologies that greatly improve sampling accuracy. And, because our microscopes are designed, tested and optimized to work with Nicolet's FT-IR spectrometers, you get the highest performance IR system available anywhere, bar none.

No problem is too small! Our staff of microscopy experts will belp you achieve the best results possible. Contact us for more information.

\section{Nicolet MPFFECIRA}




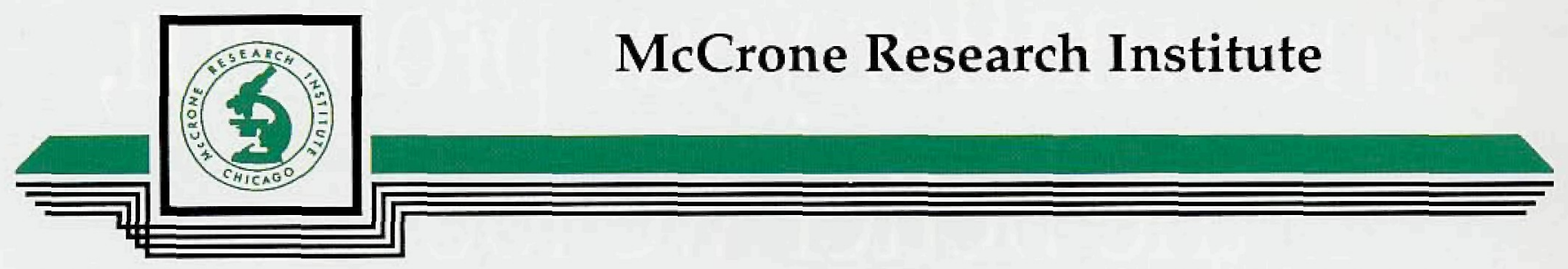

\section{CHICAGO MICROSCOPY COURSES}

101: Photomicrography — March 20-24, June 26-30

201: Applied Polarized Light Microscopy - January 16-20, March 6-10, April 17-21, May 8-12, June 5-9, August 14-18, September 11-15, October 16-20, November 13-17, December 11-15

(Also in Hayward, California - January 30-February 3 and October 23-27)

207A:* Microchemical Methods - August 14-18 (Also in Santa Ana, Califomia - March 27-31)

207B:* Advanced Microchemical Methods - September 25-29

402: Scanning Electron Microscopy - July 17-21

407B:* TEM Asbestos Analysis - March 27-31, November 6-10

408:* TEM SAED — May 8-12

501A: Identification of Small Particles - February 6-10

501B:* Advanced Small Particle Identification - September 18-22

501E:* Sample Preparation and Manipulation of Particles - November 27-December 1

503: Pharmaceutical Microscopy - February 13-17, July 31 - August 4 (Also in Hayward, California - January 16-20)

504: Forensic Microscopy - April 3-7, December 4-8 (Also in Santa Ana, California -March 13-17)

505: $\quad$ Polymer, Fiber \& Film Microscopy - November 6-10

505B:* Microscopy and Microchemistry of Polymers - November 13-17

506: Microscopy for Art Conservators - October 2-6

507:* Fiber Identification - October 9-13 (Also in Hayward, California -January 23-17)

508A: Microscopical Identification of Asbestos - January 23-27, February 27 - March 3, March 27-31, May 1-5, May 22-26, June 26-30, July 17-21, August 21-25, September 25-29, October 9-13, October 23-27,

November 27 - December 1 (Also in Hayward, California - January 9-13, February 6-10, October 16-20, November 6-10 and Seattle, Washington-September 11-15)

508B:* Advanced Asbestos Identification - January 30-February 3, April 24-28, June 5-9, December 4-8 (Also in Hayward, California - November 13-17 and Seattle, Washington-September 18-22)

511:* Wood and Pollen Microscopy - April 24-28

512:* Special Asbestos Problems — July 31- August 4

516: Asbestos Fiber Counting (NIOSH 582) - March 20-24, May 15-19, June 12-16, July 17-21, October 2-6, December 11-15 (Also in Hayward, California - February 13-17)

520B:* Microscopical Study of Paints and Extenders - August 28-September 1 (Also in Santa Ana - March 20-24)

522:* Microscopy of Explosives - October 30-November 3

523: Mineral Identification - July 24-28

526:* Drug Identification - June 19-23

527B:* Forensic Examination of Building Materials - March 13-17 1995

528:* Quantitative Asbestos Analysis - April 3-5, August 28-30, (Also in Hayward, California-February 21-23)

530** Microscopy of Environmental Dust - August 7-11

701:* Computers in Microscopy - June 12-16 (Also in Hayward, California - February 27-March 3)

*Prerequisite: course 201 or equivalent; 207A for 207B; $508 \mathrm{~A}$ for $508 \mathrm{~B}$ or 528 ; and $407 \mathrm{~A}$ for $407 \mathrm{~B}$. Courses are one week in length with tuition of $\$ 1050$ with some exceptions: Quantitative Asbestos Analysis (528) 3 days at $\$ 650$, Asbestos Fiber Counting (516) at $\$ 850$, TEM (407A) at $\$ 1250$, and (407B or 408) at $\$ 1750$. Visa and Mastercard now accepted. 